\title{
Article \\ $\beta$-Cyclodextrin Inclusion Complexes of Budesonide with Enhanced Bioavailability for COPD Treatment
}

\author{
Georgia Michailidou $^{1}\left(\mathbb{D}\right.$, George Z. Papageorgiou ${ }^{2}\left(\mathbb{D}\right.$ and Dimitrios N. Bikiaris ${ }^{1, *(1)}$ \\ 1 Laboratory of Polymer Chemistry and Technology, Department of Chemistry, Aristotle University of \\ Thessaloniki, GR-54124 Thessaloniki, Greece; michailidougeorgia18@gmail.com \\ 2 Department of Chemistry, University of Ioannina, P.O. Box 1186, GR-45110 Ioannina, Greece; gzpap@uoi.gr \\ * Correspondence: dbic@chem.auth.gr; Tel.: +30-231-099-7812; Fax: +30-231-099-7667
}

Citation: Michailidou, G.;

Papageorgiou, G.Z.; Bikiaris, D.N.

$\beta$-Cyclodextrin Inclusion Complexes of Budesonide with Enhanced Bioavailability for COPD Treatment. Appl. Sci. 2021, 11, 12085. https:// doi.org/10.3390/app112412085

Academic Editor: Alberto Milani

Received: 15 November 2021 Accepted: 15 December 2021 Published: 18 December 2021

Publisher's Note: MDPI stays neutral with regard to jurisdictional claims in published maps and institutional affiliations.

Copyright: (c) 2021 by the authors. Licensee MDPI, Basel, Switzerland. This article is an open access article distributed under the terms and conditions of the Creative Commons Attribution (CC BY) license (https:// creativecommons.org/licenses/by/ $4.0 /)$.

\begin{abstract}
Chronic obstructive pulmonary disease (COPD) is a life-threatening disease of the respiratory system, affecting many patients worldwide. Budesonide (BUD), a synthetic glucocorticosteroid applied for the treatment of COPD patients, is a hydrophobic compound with low bioavailability. The formation of inclusion complexes of hydrophobic compounds with $\beta$-cyclodextrin (CD) through the solvent evaporation technique is an appealing method for the amelioration of the compounds' in vitro release behavior. In the present study, CD-BUD complexes were prepared through the solvent evaporation technique. The effect of the applied solvent was evaluated through FTIR, scanning electron microscopy (SEM), X-ray diffraction (XRD) analysis, and in vitro release behavior measurements. It was found that the optimum complexes with the minimum degree of crystallinity and the optimum in vitro release behavior are prepared in the solvent ratio $\mathrm{H}_{2} \mathrm{O} / \mathrm{EtOH} 80 / 20 \mathrm{v} / \mathrm{v}$. In a further step, the formation of CD-BUD complexes containing different amounts of BUD was prepared. Through XRD measurements, the degree of crystallinity of the samples was calculated confirming the diminished crystallinity of BUD in CD complexes. The in vitro release of the samples showed the improved release behavior of BUD from the complexes in comparison to neat BUD while a direct correlation between the degree of crystallinity and in vitro release behavior was demonstrated.
\end{abstract}

Keywords: budesonide; COPD treatment; cyclodextrin; drug dissolution enhancement; drug release; inclusion complexes; sustain release

\section{Introduction}

Chronic obstructive pulmonary disease (COPD) is a life-threatening chronic respiratory disease and the fourth most common cause of death within the last decade [1]. According to the Global Initiative for Chronic Obstructive Lung Disease (GOLD), COPD is defined as "a common, preventable, and treatable disease that is characterized by persistent respiratory symptoms and airflow limitation that is due to airway and/or alveolar abnormalities usually caused by significant exposure to noxious particles or gases" [2]. The disease triggers pathological processes such as hypoxia, electrolyte disturbances, and changes in pulmonary hemodynamics and is often accompanied by extra-pulmonary manifestations such as thromboembolic and hemorrhagic events [1]. According to American Lung Association, smoking is the leading cause of COPD while a genetic condition called alpha-1 deficiency, exposure to air pollution, breathing secondhand smoke, and working with chemicals, dust, and fumes are the main risk factors for COPD.

Pharmacologic management of COPD aims for the reduction of the current symptoms and future exacerbation risks [3]. Treatment of the disease is conducted with inhaled bronchodilators, corticosteroids [4], or long-acting beta-agonists. If the patients have severe symptoms or intense exacerbations, combination therapy has been recommended because it lowers the incidence of exacerbations [3,5]. Budesonide (BUD) belongs to a class of drugs known as corticosteroids. It works directly in the lungs, making breathing easier by 
reducing the irritation and swelling of the airways [6]. BUD is a highly hydrophobic compound with poor absorption and minimal oral bioavailability in humans and animals [7]. Consequently, the inclusion of BUD in polymeric nanoparticles aiming in the amelioration of its bioavailability has been examined extensively by many research groups. Our group prepared BUD-loaded chitosan nanoparticles [8], Campos et al. prepared chitosan-coated PLGA nanoparticles [9], while Wang et al. prepared BUD-loaded polydopamine nanoparticles [10], and Monou et al. prepared spray-dried BUD-loaded microparticles composed of dipalmitoylphospatidylcholine, chitosan, lactose, and L-leucine.

Cyclodextrins (CDs) are cyclic oligosaccharides consisting of glucopyranosyl units linked with $\alpha-(1,4)$ bonds [11]. The natural CDs $\alpha-, \beta-$, and $\gamma$-CDs are composed of 6 , 7 , and 8 glucose units, respectively [12]. CDs have a unique torus structure composed of an inner hydrophobic cavity and a hydrophilic external surface with primary and secondary hydroxyl groups. Attributed to their structure, CDs are able to host lipophilic, non-polar molecules in their inner cavity by forming inclusion complexes [13,14]. The thermodynamic equilibrium between the different components of the system $(C D$, guest molecule, solvent) [15] affects drastically the successful formation of inclusion complexes. The formulated inclusion complexes are stable in aqueous environments owed to CD's hydrophilic external surface, and consequently, CDs are widely used in pharmaceuticals, drug delivery systems, cosmetics, and the food and chemical industries [12].

In this study, CD inclusion complexes were prepared through the solvent evaporation technique and BUD was entrapped in their interior (Figure 1). The effect of the solvent's different ratio during the formation of the inclusion complexes was examined for the first time. Moreover, different percentages of BUD were entrapped through the optimum conditions, and the resulted inclusion complexes were characterized. The main purpose was the preparation of an effective carrier for BUD, aiming in the amelioration of its in vitro release behavior and consequently its bioavailability.
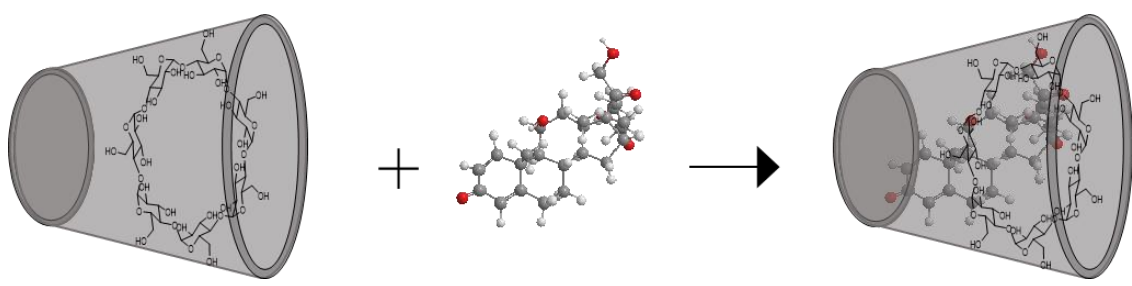

Figure 1. Schematic representation of CD-BUD inclusion complexes formation.

\section{Materials and Methods}

2.1. Materials and Reagents

$\beta$-Cyclodextrin (CD) (cavamax W7) was supplied by Wacker Chemie AG (Munich, Germany). The budesonide drug ( $99.99 \%$ purity) was kindly donated by Medicair Bioscience S.A. (Athens, Greece). All other materials used were of analytical grade.

\subsection{Preparation of Inclusion Complexes}

$\mathrm{CD}$ inclusion complexes were prepared according to the well-established solvent evaporation method [16]. In brief, $\mathrm{CD}$ was dissolved in $\mathrm{H}_{2} \mathrm{O} / \mathrm{EtOH}$ solution forming a $0.8 \% w / v$ solution. The effect of the solvent ratio was measured in a constant BUD concentration at $10 \%$ wt while the examined $\mathrm{H}_{2} \mathrm{O} / \mathrm{EtOH}$ ratios were $50 / 50,60 / 40,70 / 30$, $80 / 20$ and 90/10 $v / v$. BUD was dissolved in the minimum required volume of ethanol and was added in the CD solution. In the optimum solvent ratio, different amounts of BUD were entrapped in CD complexes in the final concentrations at $5 \mathrm{wt} \%, 10 \mathrm{wt} \%, 20 \mathrm{wt} \%$ and $30 \mathrm{wt} \%$ of BUD to the CD polymeric matrix. The solutions were heated in a water bath $\left(50^{\circ} \mathrm{C}\right)$ under constant stirring until all the solvent had evaporated and a white fine powder was obtained. 


\subsection{Inclusion Complexes Characterization}

\subsubsection{Fourier-Transform Infrared Spectroscopy (FTIR)}

FTIR spectra of the samples were obtained using an FTIR spectrometer (model FTIR2000, Perkin Elmer, Waltham, MA, USA). A small amount of each sample was triturated with a proper amount of potassium bromide $(\mathrm{KBr})$ and the disks were formed under pressure. The spectra were collected in the range of 400 to $4000 \mathrm{~cm}^{-1}$ at a resolution of $4 \mathrm{~cm}^{-1}$ using $16 \mathrm{co}$-added scans and the baseline was corrected and converted into absorbance mode.

\subsubsection{Nuclear Magnetic Resonance (NMR)}

NMR spectra were recorded in deuterated water $\mathrm{D}_{2} \mathrm{O}$. An Agilent500 spectrometer was utilized (Agilent Technologies, Santa Clara, CA, USA) at room temperature. Spectra were internally referenced with tetramethylsilane (TMS) and calibrated using the residual solvent peaks.

\subsubsection{Wide-Angle X-ray Scattering (XRD)}

$\mathrm{X}$-ray powder diffraction (XRD) patterns were recorded using an XRD-diffractometer (Rigaku-Miniiflex II, Chalgrove, Oxford, $\mathrm{UK}$ ) with a $\mathrm{CuK} \alpha$ radiation for crystalline phase identification $(\lambda=0.15405 \mathrm{~nm})$. Each sample was scanned at the range of 5 to $50^{\circ}$ with a scan speed of $1^{\circ} / \mathrm{min}$. The degree of crystallinity of the samples was calculated according to the Equation (1) [17]

$$
\% \text { Crystallinity }=\left(\mathrm{I}_{\mathrm{T}}-\mathrm{I}_{\mathrm{A}}\right) / \mathrm{I}_{\mathrm{T}}
$$

where $\mathrm{I}_{\mathrm{T}}$ corresponds to the total area of the diffractogram while $\mathrm{I}_{\mathrm{A}}$ corresponds only to the amorphous phase.

\subsubsection{Differential Scanning Calorimetry (DSC)}

For differential scanning calorimetry analysis, a Perkin-Elmer Pyris 1 differential scanning calorimeter (DSC) (Waltham, MA, USA), calibrated with indium and zinc standards, was used. About $10 \mathrm{mg}$ of each sample was used, placed in a sealed aluminum pan and heated up from 30 to $105^{\circ} \mathrm{C}$ with a heating rate of $20^{\circ} \mathrm{C} / \mathrm{min}$ in an inert atmosphere (N2, flow rate $50 \mathrm{~mL} / \mathrm{min}$ ), held in $105^{\circ} \mathrm{C}$ for $1 \mathrm{~min}$ in order to remove the absorbed water, cooled to $30^{\circ} \mathrm{C}$ with a cooling rate of $50{ }^{\circ} \mathrm{C} / \mathrm{min}$ and heated up again from 30 to $285^{\circ} \mathrm{C}$. The data reported in this work were acquired from the second heating scan.

\subsubsection{Thermogravimetric Analysis (TGA)}

Thermogravimetric analysis (TGA) was conducted in a Perkin-Elmer Pyris 1 TGA thermogravimetric analyzer (Waltham, MA, USA). Samples of $10 \pm 0.5 \mathrm{mg}$ were placed in alumina pans. An empty alumina pan was used as a reference. Heating was conducted from ambient temperature up to $600^{\circ} \mathrm{C}$ in a $50 \mathrm{~mL} / \mathrm{min}$ flow of $\mathrm{N}_{2}$. The heating rate was set at $20^{\circ} \mathrm{C} / \mathrm{min}$ and continuous records of sample temperature, sample weight, and heat flow were recorded.

\subsubsection{Scanning Electron Microscopy (SEM)}

Scanning electron microscopy (SEM) images were acquired with an electron microscope JEOL 2011 (Akishima, Tokyo, Japan). CD-BUD samples were placed on the holder and covered with carbon for providing a good conductivity of the electron beam. Operating conditions were set at accelerating voltage $20 \mathrm{kV}$, probe current $45 \mathrm{nA}$ and counting time $60 \mathrm{~s}$.

2.3.7. High-Pressure Liquid Chromatography (HPLC), Quantitative Analysis and Drug Loading

Quantitative analysis and drug loading was performed using a Shimadzu HPLC (Kyoto, Japan) prominence system consisting of a degasser (DGU-20A5, Kyoto, Japan), a liquid chromatograph (LC-20 AD, Kyoto, Japan), an autosampler (SIL-20AC, Kyoto, Japan), 
a UV/Vis detector (SPD-20A, Kyoto, Japan) and a column oven (CTO-20AC, Kyoto, Japan). For the analysis, the validated method of Leng et al. was used [18]. In detail, the CNW Technologies Athena C18, $120 \mathrm{~A}, 5 \mu \mathrm{m}, 250 \mathrm{~mm} \times 4.6 \mathrm{~mm}$ at a column temperature of $25^{\circ} \mathrm{C}$ was used. The mobile phase consisted of $\mathrm{ACN} / \mathrm{H}_{2} \mathrm{O}$ (acidified with phosphoric acid with final $\mathrm{pH}=3.2) 60 / 40 \mathrm{v} / \mathrm{v}$, at a flow rate of $1.0 \mathrm{~mL} / \mathrm{min}$. UV detection was performed at $250 \mathrm{~nm}$. The injection volume was $20 \mu \mathrm{L}$. The calibration curve was created by diluting a stock methanol solution of $100 \mathrm{ppm}$ BUD to concentrations of $0.01,0.05,0.1,0.25,0.5,1.0$, 2.5, 5.0, 10.0, 20.0 and $30.0 \mathrm{ppm}$ using ultrapure water.

For the determination of the drug-loading capacity of the samples, $10 \mathrm{mg}$ of each sample were dissolved in $10 \mathrm{~mL}$ of $\mathrm{H}_{2} \mathrm{O}$ :methanol (50:50 v/v). The resulting solution was stirred for $24 \mathrm{~h}$ and filtered (nylon filters, $0.45 \mathrm{~nm}$ pore size).

\subsubsection{Drug-Loading Percentage}

Inclusion complexes' drug loading was evaluated by applying the following equation:

Drug loading $(\%)=$ [Weight of drug in complexes $/$ Total weight of complexes] $\times 100$

\subsubsection{Phase-Solubility Studies}

The aqueous solubility of BUD in water was determined at increasing concentrations of the CD through the solubility method of Higuchi and Connors [19]. An excess amount of BUD was added into vials containing aqueous solution of $C D$ at increasing concentrations $((2.0$ to $10.0 \mathrm{mM})$. All solubility measurements were performed in triplicate. The vials were rotated at $100 \mathrm{rpm}$ while being kept at $30^{\circ} \mathrm{C}$. After equilibrium was reached $(72 \mathrm{~h})$, the solutions were filtered through a membrane filter and analyzed for drug content by highperformance liquid chromatography (HPLC). A phase-solubility diagram was constructed by plotting the concentration of BUD dissolved versus the $\mathrm{CD}$ concentration.

\subsubsection{In Vitro Dissolution Studies}

For the in vitro release studies, DISTEK Dissolution Apparatus I (North Brunswick, NJ, USA) equipped with an autosampler was used. Inclusion complexes were inserted in dialysis tubing (molecular weight cut-off 12,000-14,000, Servapor) and placed in the baskets of the apparatus. Dissolution was performed at $37 \pm 1{ }^{\circ} \mathrm{C}$ and the rotation speed was set at $50 \mathrm{rpm}$. The dissolution medium was $300 \mathrm{~mL}$ of a phosphate buffer, $\mathrm{pH}=7.4$. Two milliliters of aqueous solution were withdrawn from the release media and quantified.

\section{Results and Discussion}

\subsection{The Effect of Solvent Ratio in Budesonide Cyclodextrin Inclusion Complexes}

The formation of inclusion complexes between $C D$ and various hydrophobic compounds has been examined extensively since it aids in the development of stable formulations with enhanced bioavailability [20]. During the formation of the complexes, it is significant to estimate how the effective inclusion affects the properties of drugs when $C D$ complexes are formulated [21]. Figure 2 depicts the phase-solubility diagram of BUD with CD. According to Higuchi and Connors, the obtained curve is characterized as an "A type" phase-solubility profile, describing the increase of BUD solubility as the CD concentration increases. The A-type models indicate that one drug molecule forms a complex with one molecule of $\mathrm{CD}$ and a linear relationship exhibits [22].

Beta-CD is the least water soluble among the cyclodextrins and BUD is a waterinsoluble active compound. Consequently, their further effective complexation would take place in the presence of an organic solvent. The applied solvent ratio is of crucial importance since the organic solvent, in this work ethanol, competes with drug molecules for their successful inclusion in the hydrophobic cavity of CD [23]. In the present study, the utilized solvent system is $\mathrm{H}_{2} \mathrm{O} / \mathrm{EtOH}$. The amount of the organic solvent affects the inclusion efficacy of the hydrophobic compound, i.e., BUD in the interior cavity of $\mathrm{CD}$ as well as the crystallinity of the final samples, thereafter [14]. Consequently, different 
$\mathrm{H}_{2} \mathrm{O} / \mathrm{EtOH}$ ratios (50/50, 60/40, 70/30, 80/20, and 90/10 v/v) were examined for obtaining the optimum inclusion efficacy, with the minimum amount of crystallinity. For this purpose, the inclusion of BUD in the CD cavity in a $10 \% \mathrm{wt}$ ratio was conducted.

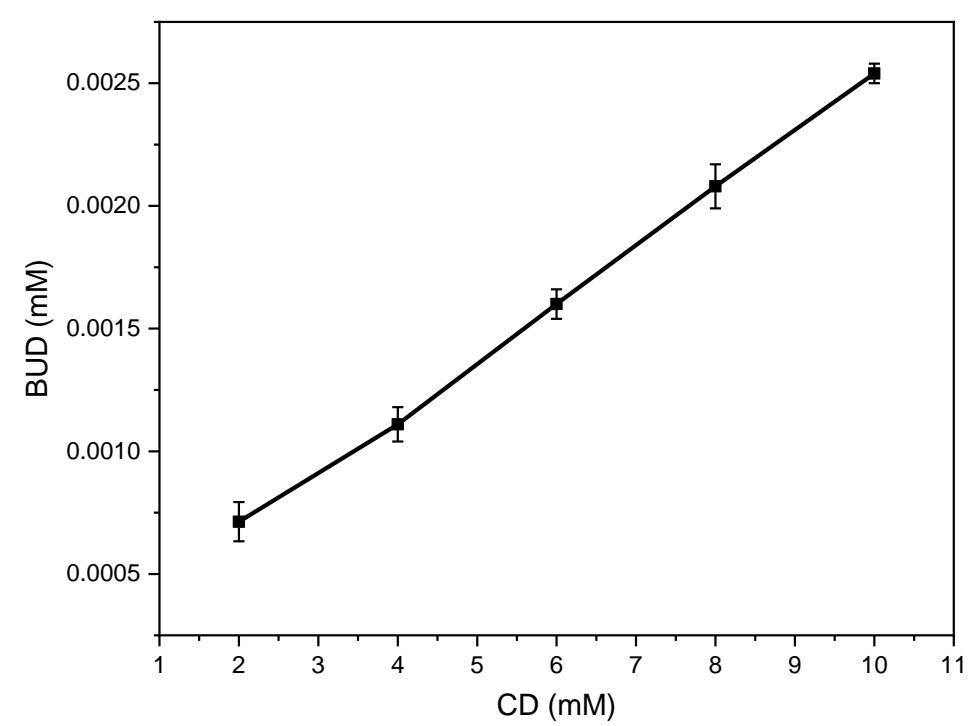

Figure 2. Phase-solubility diagram of BUD with $\mathrm{CD}$, at $30^{\circ} \mathrm{C}$.

Figure 3 depicts the FTIR spectra of CD-BUD samples for the various $\mathrm{H}_{2} \mathrm{O} / \mathrm{EtOH}$ ratios. The spectra on neat $C D$ showed the characteristic peaks of the oligosaccharide present at $3400 \mathrm{~cm}^{-1}$ attributed to $\mathrm{O}-\mathrm{H}$ stretching vibration, at $2930 \mathrm{~cm}^{-1}$ to the $\mathrm{C}-\mathrm{H}$ stretching vibration, at $1640 \mathrm{~cm}^{-1}$ the $\mathrm{O}-\mathrm{H}$ bending vibration, at $1155 \mathrm{~cm}^{-1}$ the $\mathrm{C}-\mathrm{H}$ vibration and at $1029 \mathrm{~cm}^{-1}$ the $\mathrm{C}-\mathrm{O}$ vibration [24]. BUD characteristic peaks are present at $3499 \mathrm{~cm}^{-1}$ region of the $\mathrm{O}-\mathrm{H}$ stretching vibration, at $2955 \mathrm{~cm}^{-1}$ methyl groups stretching vibration $(\mathrm{C}-\mathrm{H})$, at $1722 \mathrm{~cm}^{-1}$ and $1670 \mathrm{~cm}^{-1}$ stretching vibration of carbonyl groups $(\mathrm{C}=\mathrm{O})$ and at $1626 \mathrm{~cm}^{-1}$ stretching vibration of the double bond $(C=C)$ [25]. Comparing the spectra of neat $\mathrm{CD}$, with the inclusion complexes, characteristic peaks attributed to the presence of BUD appear (Figure 3). More specifically, the peaks present at $2956 \mathrm{~cm}^{-1}, 1720 \mathrm{~cm}^{-1}$ and $1670 \mathrm{~cm}^{-1}$ are attributed to BUD. The peaks are slightly shifted in comparison to the neat drug, owing to interactions among the oligosaccharide and BUD.

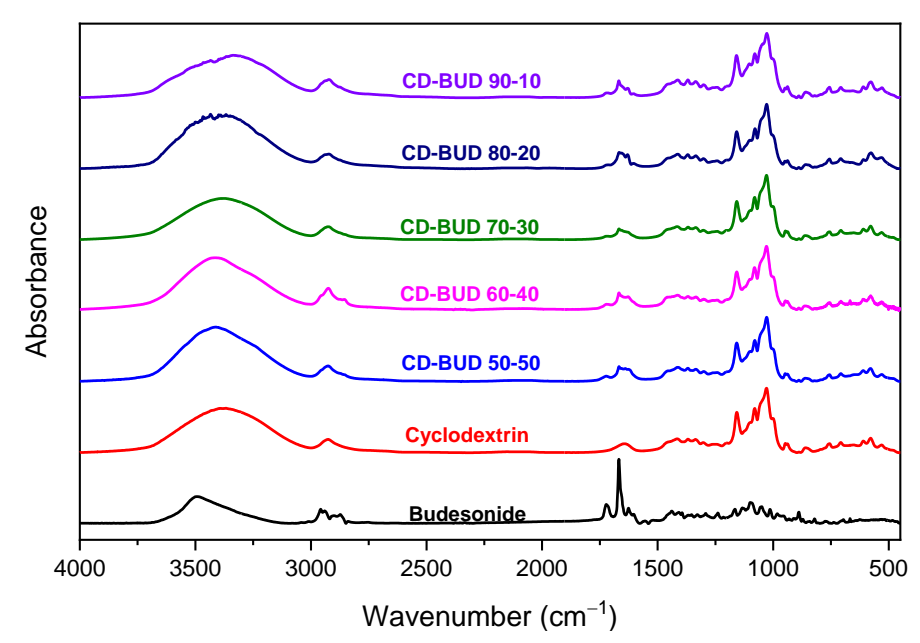

Figure 3. FTIR spectra of BUD, CD and CD-BUD inclusion complexes containing $10 \mathrm{wt} \% \mathrm{BUD}$ after treatment at different $\mathrm{H}_{2} \mathrm{O} / \mathrm{EtOH}$ ratios $(50 / 50,60 / 40,70 / 30,80 / 20$ and 90/10 v/v).

In a further step, the successful complexation was confirmed through ${ }^{1} \mathrm{H}-\mathrm{NMR}$ measurements. In Figure 4, the H-3 and H-5 are the protons which are found inside the cavity of 
$\mathrm{CD}$ and are the ones that are generally affected by complexation. In the ${ }^{1} \mathrm{H}-\mathrm{NMR}$ spectrum of the CD-BUD complex, a slight upfield shift of the H-3 and H-5 protons is observed. This shift confirms the successful complexation of BUD in the CD cavity.

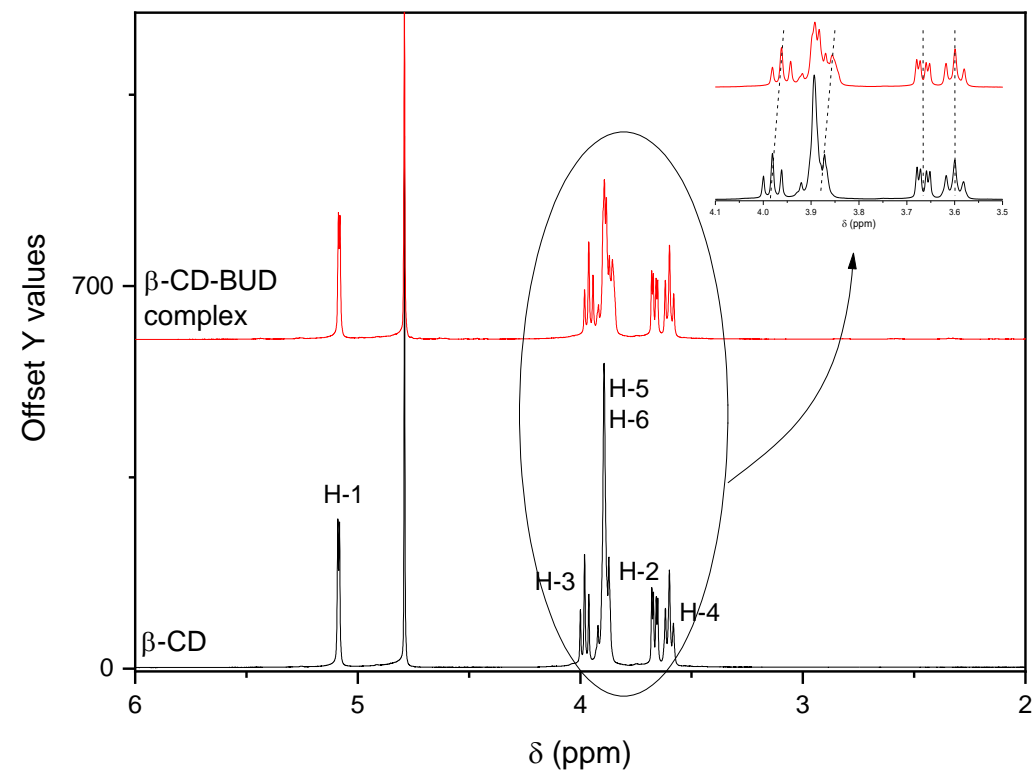

Figure 4. ${ }^{1} \mathrm{H}-\mathrm{NMR}$ spectra of $\mathrm{CD}$ and CD-BUD complex containing $10 \mathrm{wt} \%$ BUD. The peak at $4.79 \mathrm{ppm}$ is attributed to $\mathrm{D} 2 \mathrm{O}$.

SEM images were used for the examination of the inclusion complexes' morphology. According to the literature, CD presents an irregular block structure [26]. As depicted in Figure 5, in any solvent ratio, the obtained complexes were of irregular, spherical shaped, agglomerated particles. This observation is in accordance to the work of Musuc et al. [27] concerning CD inclusion complexes containing a flavonoid, cirsiliol, confirming the successful formation of the complexes.

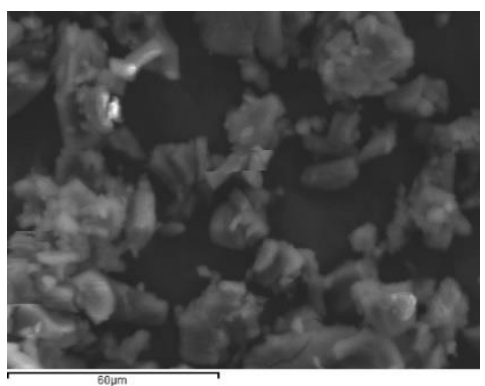

(a)

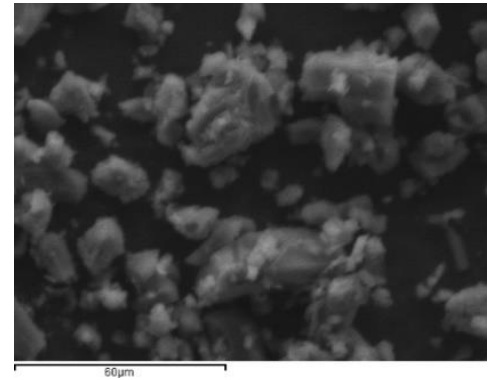

(d)

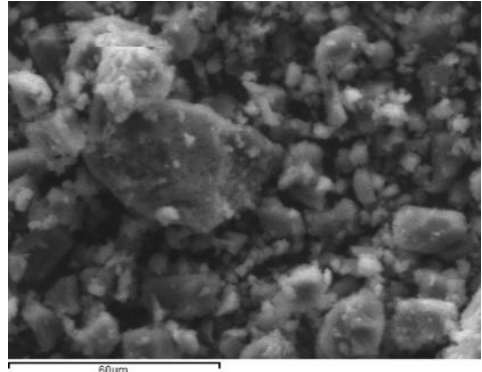

(b)

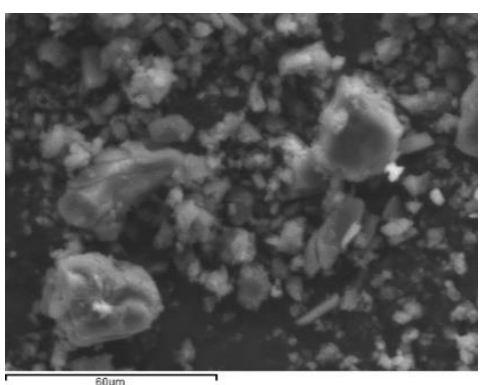

(c)

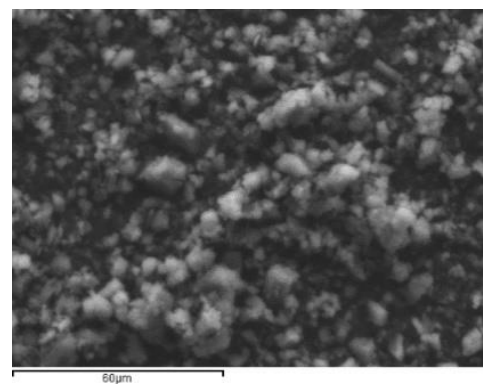

(e)

Figure 5. SEM images of CD-BUD inclusion complexes in $\mathrm{H}_{2} \mathrm{O} / \mathrm{EtOH}$ ratios (a) 50/50, (b) 60/40, (c) 70/30, (d) 80/20, (e) $90 / 10$. 
In a subsequent stage, through the X-ray diffraction analysis, the physical state of the inclusion complexes was assessed (Figure 6) and the degree of crystallinity was calculated according to Equation (1). CD is a crystalline oligosaccharide with many characteristic peaks in its diffractogram in $12.66^{\circ}, 15.96^{\circ}, 16.12^{\circ}, 18.24^{\circ}, 19.00^{\circ}, 21.14^{\circ}, 23.00^{\circ}, 24.22^{\circ}, 25.7^{\circ}$ and $27.10^{\circ}$ [28]. BUD is a crystalline pharmaceutical compound with a main sharp peak at $15.8^{\circ}$, secondary peaks at $12.2^{\circ}, 23.2^{\circ}$, and many smaller peaks as well [29]. Concerning the inclusion complexes, the assessment of their crystalline structure is hard to be observed in the diffractograms in Figure 4. The degree of crystallinity is calculated through Equation (1) (Table 1). The degree of crystallinity of neat BUD is equal to $70.4 \%$, while for neat CD, it is equal to $72.2 \%$. All the CD-BUD samples reveal lower crystallinity values owed to the complexation between the oligosaccharide and the drug molecules. Maximum complexation is conducted in sample CD-BUD-10 with the $\mathrm{H}_{2} \mathrm{O} / \mathrm{EtOH}$ 80-20 ratio, since the lower degree of crystallinity is calculated, i.e., at $45.5 \%$. The ratio of the organic solvent has an impact on the complexation of BUD and CD. The increasing ratio of EtOH proportionally affects the crystallinity of the CD-BUD samples while the ability for the successful formation of inclusion complexes decreases. This is according to the literature since the molecules of the organic solvent compete with the active compound's molecules for inclusion in the interior cavity of CD [15]. However, concerning the $\mathrm{H}_{2} \mathrm{O} / \mathrm{EtOH} 90 / 10$ ratio, the crystallinity of the sample is increasing again, attributed to the highly hydrophobic nature of BUD. In the aforementioned ratio, the amount of organic solvent is insufficient for solubilizing the drug, which remains insoluble.

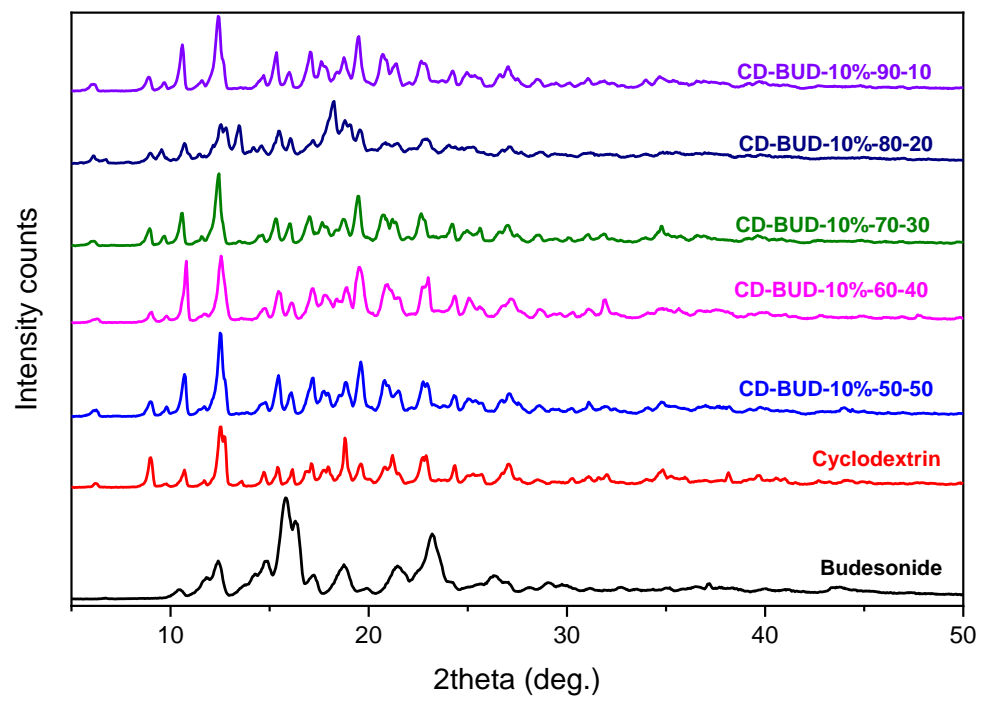

Figure 6. XRD spectra of BUD, $\mathrm{CD}$ and CD-BUD inclusion complexes at different $\mathrm{H}_{2} \mathrm{O} / \mathrm{EtOH}$ ratios $(50 / 50,60 / 40,70 / 30,80 / 20$ and $90 / 10 v / v)$.

Table 1. Degree of crystallinity of BUD, CD and CD-BUD inclusion complexes in various $\mathrm{H}_{2} \mathrm{O}$ / EtOH ratios.

\begin{tabular}{cc}
\hline Sample & \% of Crystallinity \\
\hline Budesonide & 70.4 \\
Cyclodextrin & 72.2 \\
CD-BUD-10_50-50 & 68.6 \\
CD-BUD-10_60-40 & 64.8 \\
CD-BUD-10_70-30 & 59.1 \\
CD-BUD-10_80-20 & 45.4 \\
CD-BUD-10-90-10 & 68.4 \\
\hline
\end{tabular}




\subsection{Budesonide Inclusion in Cyclodextrin Complexes}

In a subsequent stage, different amounts of BUD were entrapped in CD complexes with the optimum ratio, $\mathrm{H}_{2} \mathrm{O} / \mathrm{EtOH} 80 / 20$. BUD was entrapped in $5 \mathrm{wt} \%, 10 \mathrm{wt} \%, 20 \mathrm{wt} \%$, and $30 \mathrm{wt} \%$ forming the samples CD-BUD $5 \mathrm{wt} \%$, CD-BUD $10 \mathrm{wt} \%$, CD-BUD 20\%wt, and $\mathrm{CD}-\mathrm{BUD} 30 \mathrm{wt} \%$. FTIR measurements were performed for the evaluation of the ionic interactions between BUD and CD (Figure 7). In the FTIR spectra of the CD-BUD inclusion complexes, characteristic peaks of CD and BUD are present. Moreover, it is evident that by increasing the amount of the added BUD in the complexes, the peaks present in the regions $1565-1760 \mathrm{~cm}^{-1}$ and $2850-3000 \mathrm{~cm}^{-1}$ attributed to the drug are intensified [30].

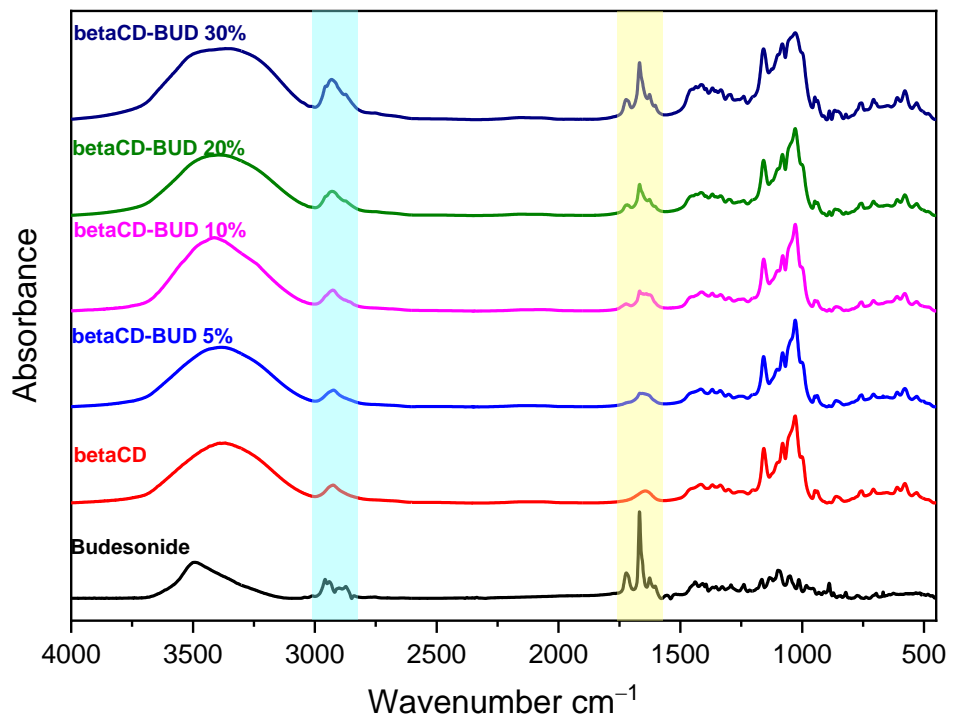

Figure 7. FTIR spectra of BUD, CD and CD-BUD $5 \mathrm{wt} \%, 10 \mathrm{wt} \%, 20 \mathrm{wt} \%$ and $30 \mathrm{wt} \%$.

In a subsequent level, the degree of crystallinity of the samples was calculated from the XRD spectra of Figure 8. The results in Table 2, as well as in Figure 8, reveal that by increasing the drug content, the peak intensities along with the degree of crystallinity increasing as a result, which is in accordance with previous data from our group when BUD was entrapped in chitosan nanoparticles [8].

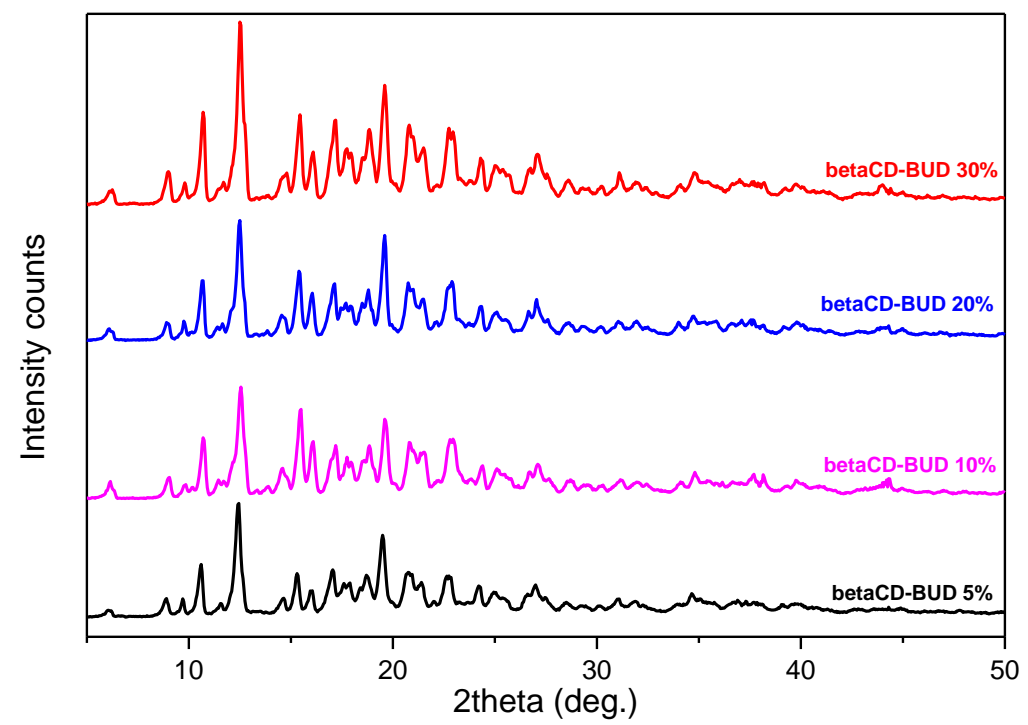

Figure 8. X-ray diffractograms of CD-BUD $5 w t \%, 10 w t \%, 20 w t \%$ and $30 w t \%$. 
Table 2. Degree of crystallinity of BUD, CD and CD-BUD $5 \mathrm{wt} \%, 10 \mathrm{wt} \%, 20 \mathrm{wt} \%$ and $30 \mathrm{wt} \%$.

\begin{tabular}{cc}
\hline Sample & Degree of Crystallinity (\%) \\
\hline CD-BUD-5\% & 43.9 \\
CD-BUD-10\% & 45.4 \\
CD-BUD-20\% & 53.6 \\
CD-BUD-30\% & 56.6 \\
\hline
\end{tabular}

The inclusion complexes were observed through SEM images, as shown in Figure 8, and their morphological characterizations remained unaffected. Neat BUD is a crystalline compound with columnar crystalline smooth surfaced rods; [31] whereas, the inclusion complexes in Figure 9 are depicted as irregular spherical shaped agglomerated particles. The XRD results established that by increasing the BUD content, the degree of crystallinity rises. Consequently, unentrapped crystalline rods were expected to be present in SEM images. However, the morphological image of the samples for the various BUD concentrations is similar. DSC analysis confirms the aforementioned statement.

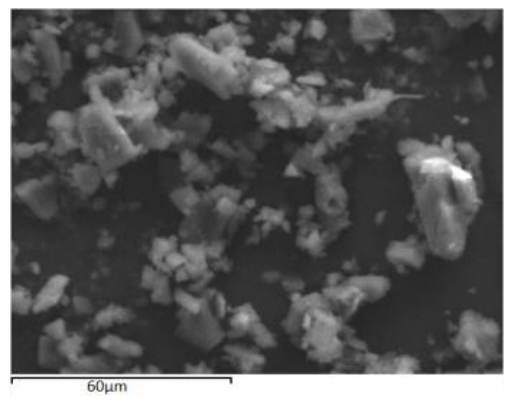

(a)

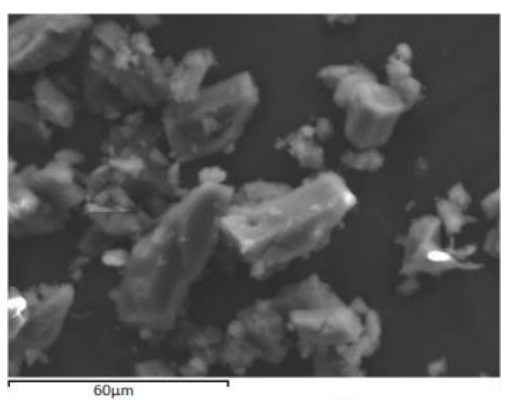

(c)

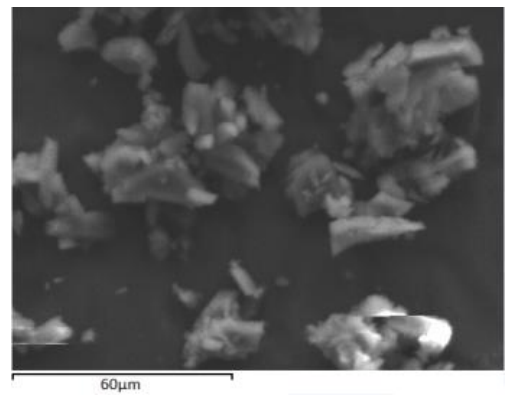

(b)

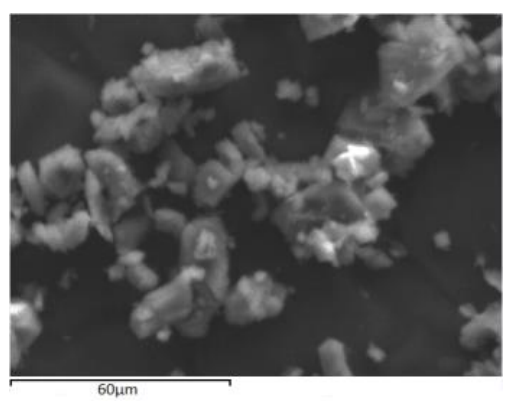

(d)

Figure 9. SEM images of (a) CD-BUD 5\% (b) CD-BUD 10\% (c) CD-BUD 20\% (d) CD-BUD 30\%.

The DSC thermograms of neat BUD and CD-BUD samples are presented in Figure 10a,b, respectively. Neat BUD has a melting peak at $257^{\circ} \mathrm{C}$ [32] and a prior exothermic peak at $233^{\circ} \mathrm{C}$. The exothermic peak is attributed to the energy produced during the transition of BUD's less stable crystals to a more stable crystal phase (exothermic process). Further heating leads to the melting point [33]. DSC curves of the CD-BUD samples indicate that when forming inclusion complexes with CD, BUD is entrapped in the internal cavity in the amorphous phase [34]. The melting point of BUD is diminished and shifted to lower temperatures. Moreover, the presence of melting peaks at CD-BUD complexes is attributed to the non-included amount of BUD while the melting point shifting to $218-225{ }^{\circ} \mathrm{C}$ is ascribed to the interactions of BUD with CD. 


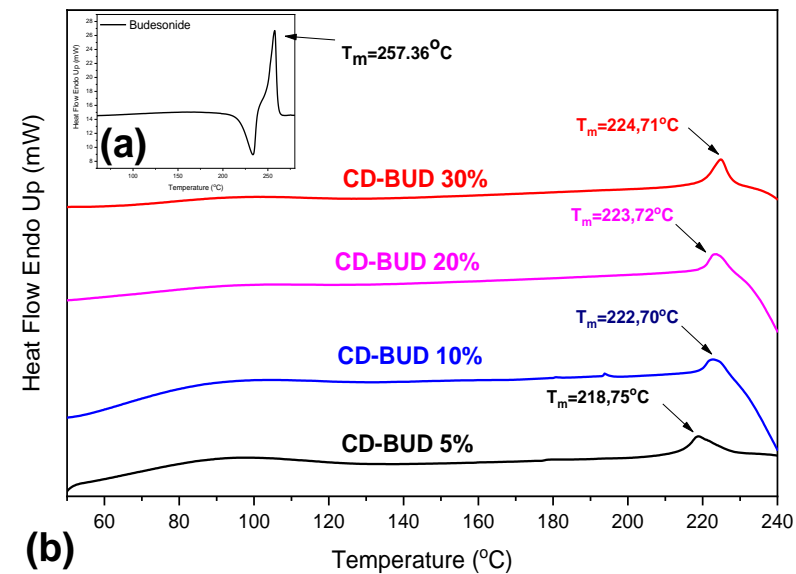

Figure 10. DSC curves of (a) BUD and (b) CD-BUD 5\%, CD-BUD 10\%, CD-BUD 20\% and CD-BUD 30\%.

Furthermore, the thermal stability of the inclusion complexes was evaluated through TGA measurements (Figure 11). Neat BUD demonstrates a one-step mass loss between 250-370 ${ }^{\circ} \mathrm{C}$, while at $600{ }^{\circ} \mathrm{C}$ the mass residue is at about $5 \%$. In contrast, neat CD has two main decomposition steps. The first is at $50-100{ }^{\circ} \mathrm{C}$ and is attributed to the samples moisture, while during the second step at $317^{\circ} \mathrm{C}$, the degradation of the oligosaccharide initiates [35]. The inclusion complexes reveal a comparable to neat CD degradation profile, with two decomposition steps. For the samples CD-BUD 5\%, CD-BUD 10\%, and CD-BUD $20 \%$, their decomposition initiates at $274^{\circ} \mathrm{C}$, while the sample CD-BUD $30 \%$ initiates its degradation at $249^{\circ} \mathrm{C}$. The formation of inclusion complexes changed the thermal degradation properties of neat BUD and CD, diminishing the thermal stability of CD and enhancing the thermal stability of BUD.

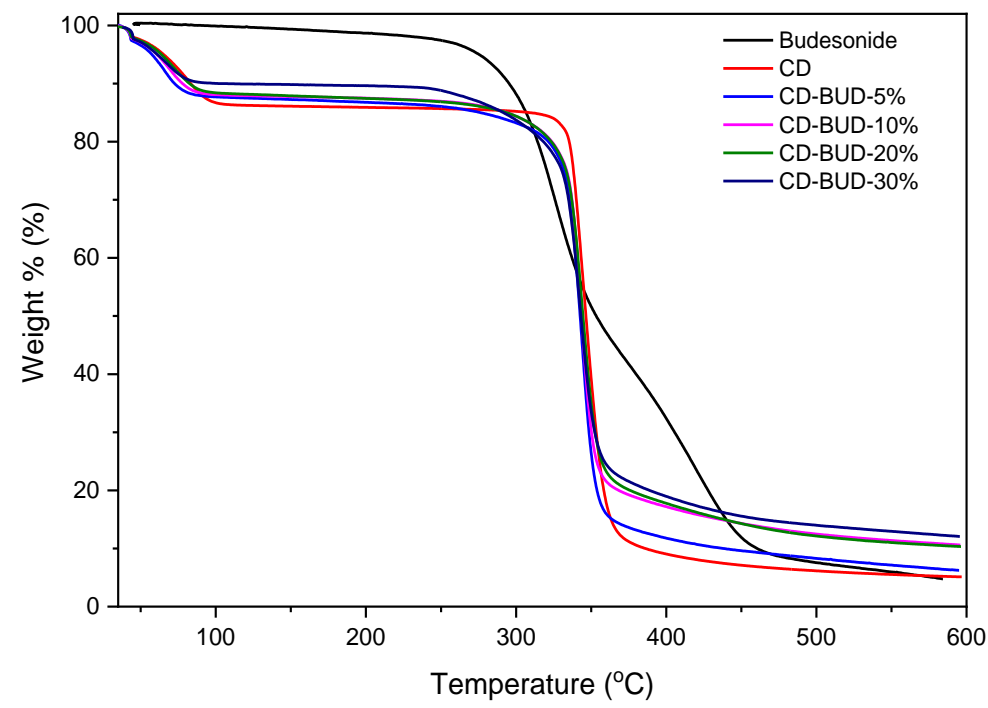

Figure 11. TGA curves of BUD, CD and CD-BUD 5\%, CD-BUD 10\%, CD-BUD 20\% and CD-BUD 30\%.

\subsection{In Vitro Drug Release Analysis}

The drug-loading percentage of BUD in the interior cavity of CD is a significant parameter directly affecting the release profile with a major impact on the systemic absorption inducing higher bioavailability [36]. In the present study, the effect of different solvent ratios was examined. Table 3 summarizes the drug-loading efficiency in the CD-BUD-10\% for $\mathrm{H}_{2} \mathrm{O} / \mathrm{EtOH}$ ratios varying from $50 / 50$ to $90 / 10$. It is evident that, by diminishing the amount of the organic solvent from $50 / 50$ to $80 / 20$ ratio, the drug loading increases. The organic solvent competes with the hydrophobic BUD molecules to enter the hydrophobic $\mathrm{CD}$ cavity. Consequently, with a lower ratio of EtOH, BUD can be more easily entrapped in 
CD complexes. However, in the ratio 90/10, the drug-loading percentage decreases, which is attributed to the inability of BUD to be completely dissolved under these conditions, forming inclusion complexes with a lower drug loading percentage.

Table 3. Drug loading percentage of CD-BUD-10_50-50, CD-BUD-10_60-40, CD-BUD-10_70-30, CD-BUD-10_80-20 and CD-BUD-10_90-10.

\begin{tabular}{cc}
\hline Sample & Drug Loading (\%) \\
\hline CD-BUD-10_50-50 & 8.8 \\
CD-BUD-10_60-40 & 8.9 \\
CD-BUD-10_70-30 & 8.8 \\
CD-BUD-10_80-20 & 9.1 \\
CD-BUD-10-90-10 & 7.8 \\
\hline
\end{tabular}

In a further step, the dissolution profile of the inclusion complexes was conducted (Figure 12). The in vitro release profile of BUD from the CD-BUD complexes is highly associated with the degree of crystallinity of the samples. Active compounds entrapped in the amorphous phase are estimated to have an enhanced dissolution profile since the amorphous state of the drugs is characterized by a disordered structure in comparison to the crystalline state with higher free energy [37]. BUD as a crystalline, hydrophobic compound presents an in vitro dissolution ability of up to $13 \%$. The inclusion of BUD in $\mathrm{CD}$ complexes leads to the amelioration of the active compound's release behavior. As expected, the optimum release behavior was measured in the sample with $\mathrm{H}_{2} \mathrm{O} / \mathrm{EtOH}$ ratio $80 / 20$, releasing up to $65 \%$ of the embedded drug. The samples with higher degrees of crystallinity presented inferior in vitro release. However, all the inclusion complexes presented a two-phase release profile. An initial burst release during the first $7 \mathrm{~h}$ which is followed by a sustain release up to 10 days.

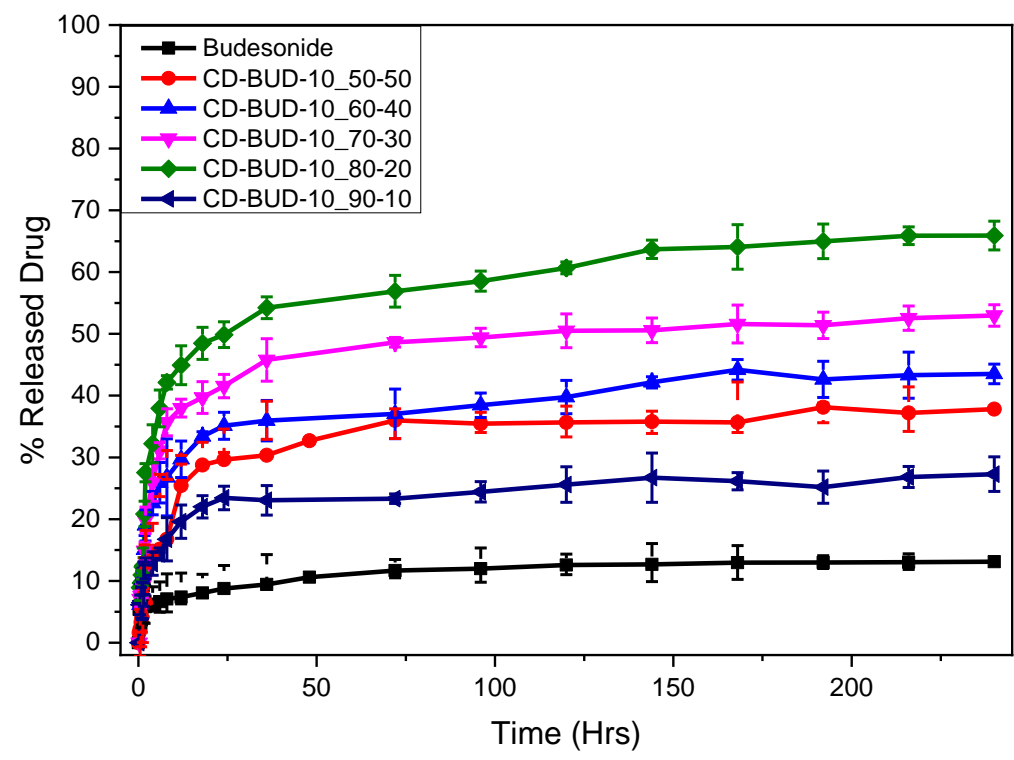

Figure 12. In vitro release of BUD from CD inclusion complexes at $\mathrm{pH}$ 7.4.

At a subsequent level, the drug loading percentage of BUD in the samples CD-BUD $5 \mathrm{wt} \%, 10 \mathrm{wt} \%, 20 \mathrm{wt} \%$, and $30 \mathrm{wt} \%$ was estimated. Table 4 presents the increasing loading percentage, as the amount of BUD added in the inclusion complexes increases. Since the ratio of the organic solvent is constant $(80 / 20 \mathrm{v} / \mathrm{v})$, the loading percentage is affected solely by the presence of BUD. The results are in agreement with the literature, since the incorporation of a lipophilic drug into inclusion complexes results in the improvement of its loading efficacy $[38,39]$. 
Table 4. Drug-loading percentage of CD-BUD-5 wt $\%$, CD-BUD-10 wt $\%$, CD-BUD-20 wt $\%$ and CD-BUD-30 $w \mathrm{t} \%$.

\begin{tabular}{cc}
\hline Sample & Drug Loading \\
\hline CD-BUD-5\% & 2.1 \\
CD-BUD-10\% & 8.8 \\
CD-BUD-20\% & 13.7 \\
CD-BUD-30\% & 19.5 \\
\hline
\end{tabular}

In vitro release was estimated in the samples CD-BUD $5 \mathrm{wt} \%, 10 \mathrm{wt} \%, 20 \mathrm{wt} \%$, and $30 \mathrm{wt} \%$. Their release profiles are similar to the in vitro release of the samples CD-BUD10 with various $\mathrm{H}_{2} \mathrm{O} / \mathrm{EtOH}$ ratios with a two-phase dissolution profile, an initial burst release, followed by a sustain release (Figure 13). Interesting is the fact that a higher release is achieved by the sample with a lower amount of BUD, CD-BUD-5\% equal to $78.7 \%$. This release behavior is characteristic for lipophilic drugs owed to hydrophobic interactions taking place between the drugs' molecules. According to literature data, the entrapment of hydrophobic active substances in polymeric matrices results in an inversely proportional relationship between drug concentration and drug release. When the drug amount becomes higher, the drug release is reduced [40-42]. Furthermore, as the percentage of BUD increases, the percentage of the released drug is diminished. The maximum dissolution percentage of the samples CD-BUD $10 \mathrm{wt} \%, 20 \mathrm{wt} \%$, and $30 \mathrm{wt} \%$ are $61.8 \%, 51.5 \%$, and $27.2 \%$ respectively. Moreover, the release profiles are according to the degree of crystallinity of the samples. As expected, samples with lower degrees of crystallinity present ameliorated release profiles. These results are according to results from our previous study where BUD was entrapped in chitosan nanoparticles and the dissolution of BUD was diminished as the drug loading percentage increased [8]. This phenomenon is characteristic for hydrophobic active compounds [43,44] where lower dissolution profiles are observed in higher amounts of drug loading, attributed to their hydrophobic nature [44].

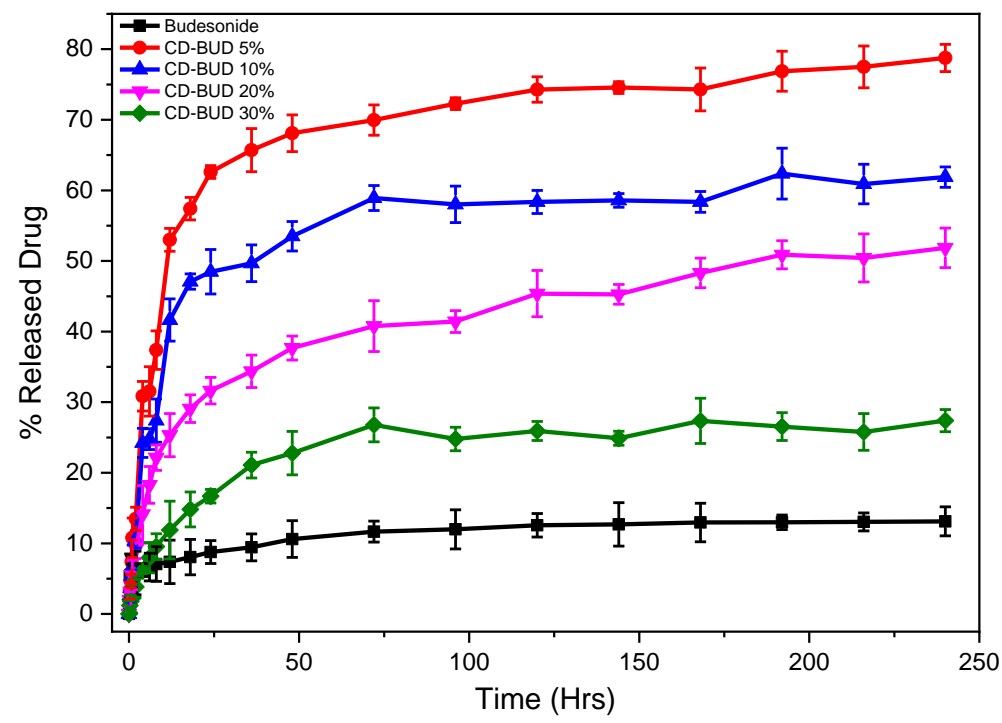

Figure 13. In vitro release of BUD from CD-BUD $5 w t \%, 10 w t \%, 20 w t \%$ and $30 w t \%$ inclusion complexes at $\mathrm{pH} 7.4$.

\section{Conclusions}

In the present study, BUD was successfully entrapped in CD inclusion complexes. The effect of the solvent ratio during the formation of the complexes on the degree of crystallinity and the drug-loading efficacy was examined. The optimum ratio of $\mathrm{H}_{2} \mathrm{O} / \mathrm{EtOH}$ was $80 / 20 \mathrm{v} / \mathrm{v}$, presenting the highest loading efficacy with the minimum degree of crys- 
tallinity. Inclusion complexes were formed in the optimum conditions in ratios $5 \mathrm{wt} \%$, $10 \mathrm{wt} \%, 20 \mathrm{wt} \%$, and $30 \mathrm{wt} \%$. FTIR spectra confirmed the presence of BUD in CD complexes with its characteristic peaks increasing as the drug content of the samples increased. Through XRD diffractograms and DSC thermograms, the diminishing of the drug's crystallinity was evident. SEM images depicted the morphology of the complexes, while through TGA thermograms the amelioration of the thermal behavior of BUD after inclusion was proved. In vitro release studies were conducted and the enhanced release of BUD in the dissolution medium was confirmed. A direct correlation between crystallinity and in vitro release behavior was observed, since higher dissolution percentages were obtained for samples with lower crystallinity values. Results support the optimized in vitro release of BUD from CD complexes, and consequently, CD-BUD inclusion complexes are promising candidates for enhancing the drug's bioavailability for the treatment of COPD patients.

Author Contributions: Methodology, investigation, original draft preparation, G.M.; Methodology, investigation, supervision, G.Z.P.; Supervision, writing - review and editing, D.N.B. All authors have read and agreed to the published version of the manuscript.

Funding: This research received no external funding.

Institutional Review Board Statement: Not applicable.

Informed Consent Statement: Not applicable.

Acknowledgments: The authors would like to thank Alexandra Zamboulis of the Department of Chemistry, Aristotle University of Thessaloniki for the ${ }^{1} \mathrm{H}-\mathrm{NMR}$ measurements.

Conflicts of Interest: The authors declare no conflict of interest.

\section{References}

1. Ye, J.; Yao, P.; Shi, X.; Yu, X. A systematic literature review and meta-analysis on the impact of COPD on atrial fibrillation patient outcome. Hear. Lung 2022, 51, 67-74. [CrossRef] [PubMed]

2. Gutiérrez Villegas, C.; Paz-Zulueta, M.; Herrero-Montes, M.; Parás-Bravo, P.; Madrazo Pérez, M. Cost analysis of chronic obstructive pulmonary disease (COPD): A systematic review. Health Econ. Rev. 2021, 11, 31. [CrossRef]

3. Zheng, J.; Baldi, S.; Zhao, L.; Li, H.; Lee, K.H.; Singh, D.; Papi, A.; Grapin, F.; Guasconi, A.; Georges, G. Efficacy and safety of single-inhaler extrafine triple therapy versus inhaled corticosteroid plus long-acting beta2 agonist in eastern Asian patients with COPD: The TRIVERSYTI randomised controlled trial. Respir. Res. 2021, 22, 90. [CrossRef] [PubMed]

4. Sivapalan, P.; Rutishauser, J.; Ulrik, C.S.; Leuppi, J.D.; Pedersen, L.; Mueller, B.; Eklöf, J.; Biering-Sørensen, T.; Gottlieb, V.; Armbruster, K.; et al. Effect of different corticosteroid regimes for hospitalised patients with exacerbated COPD: Pooled analysis of individual participant data from the REDUCE and CORTICO-COP trials. Respir. Res. 2021, 22, 155. [CrossRef] [PubMed]

5. Koarai, A.; Yamada, M.; Ichikawa, T.; Fujino, N.; Kawayama, T.; Sugiura, H. Triple versus LAMA/LABA combination therapy for patients with COPD: A systematic review and meta-analysis. Respir. Res. 2021, 22, 183. [CrossRef] [PubMed]

6. Odonnell, S.; Omorain, C.A. Therapeutic benefits of budesonide in gastroenterology. Ther. Adv. Chronic Dis. 2010, 1, 177-186. [CrossRef] [PubMed]

7. Ahmad, A.; Ansari, M.M.; Kumar, A.; Bishnoi, M.; Raza, S.S.; Khan, R. Aminocellulose-grafted polycaprolactone-coated core-shell nanoparticles alleviate the severity of ulcerative colitis: A novel adjuvant therapeutic approach. Biomater. Sci. 2021, 9, 5868-5883. [CrossRef] [PubMed]

8. Michailidou, G.; Ainali, N.M.; Xanthopoulou, E.; Nanaki, S.; Kostoglou, M.; Koukaras, E.N.; Bikiaris, D.N. Effect of Poly ( vinyl alcohol) on Nanoencapsulation of Budesonide in Chitosan Nanoparticles via Ionic Gelation and Its Improved Bioavailability. Polymers 2020, 12, 1101. [CrossRef] [PubMed]

9. Campos, E.V.R.; Proença, P.L.F.; Costa, T.G.D.; De Lima, R.; Hedtrich, S.; Fraceto, L.F.; De Araujo, D.R. Hydrogels Containing Budesonide-Loaded Nanoparticles to Facilitate Percutaneous Absorption for Atopic Dermatitis Treatment Applications. ACS Appl. Polym. Mater. 2021, 3, 4436-4449. [CrossRef]

10. Wang, S.; Wannasarit, S.; Figueiredo, P.; Molinaro, G.; Ding, Y.; Correia, A.; Casettari, L.; Wiwattanapatapee, R.; Hirvonen, J.; Liu, D.; et al. Intracellular Delivery of Budesonide and Polydopamine Co-Loaded in Endosomolytic Poly(butyl methacrylate-comethacrylic acid) Grafted Acetalated Dextran for Macrophage Phenotype Switch from M1 to M2. Adv. Ther. 2021, 4, 2000058. [CrossRef]

11. Cheirsilp, B.; Rakmai, J. Inclusion complex formation of cyclodextrin with its guest and their applications. Biol. Eng. Med. 2017, 2, 1-6. [CrossRef] 
12. Carneiro, S.B.; Duarte, F.Í.C.; Heimfarth, L.; Quintans, J.D.S.S.; Quintans-Júnior, L.J.; Júnior, V.F.D.V.; De Lima, Á.A.N. Cyclodextrin-drug inclusion complexes: In Vivo and In Vitro approaches. Int. J. Mol. Sci. 2019, 20, 642. [CrossRef] [PubMed]

13. Saha, S.; Roy, A.; Roy, K.; Roy, M.N. Study to explore the mechanism to form inclusion complexes of $\beta$-cyclodextrin with vitamin molecules. Sci. Rep. 2016, 6, 35764. [CrossRef] [PubMed]

14. Martin Del Valle, E.M. Cyclodextrins and their uses: A review. Process Biochem. 2004, 39, 1033-1046. [CrossRef]

15. Papadopoulos, N.D.; Karayianni, H.S.; Tsakiridis, P.E.; Perraki, M.; Hristoforou, E. Cyclodextrin inclusion complexes as novel MOCVD precursors for potential cobalt oxide deposition. Appl. Organomet. Chem. 2010, 24, 112-121. [CrossRef]

16. Shaikh, J.; Deshmane, S.V.; Purohit, R.N.; Biyani, K.R. Behavioural study of cyclodextrin inclusion complex on enhancement of solubility of aceclofenac. Indian Drugs 2015, 52, 19-23. [CrossRef]

17. Jollet, V.; Chambon, F.; Rataboul, F.; Cabiac, A.; Pinel, C.; Guillon, E.; Essayem, N. Non-catalyzed and $\mathrm{Pt}_{\mathrm{t}} / \gamma-\mathrm{Al}_{2} \mathrm{O}_{3}-\mathrm{Catalyzed}$ hydrothermal cellulose dissolution-conversion: Influence of the reaction parameters and analysis of the unreacted cellulose. Green Chem. 2009, 11, 2052-2060. [CrossRef]

18. Leng, D.; Thanki, K.; Foged, C.; Yang, M. Formulating Inhalable Dry Powders Using Two-Fluid and Three-Fluid Nozzle Spray Drying. Pharm. Res. 2018, 35, 247. [CrossRef] [PubMed]

19. Higuchi, T.; Connors, K.A. Phase Solubility Techniques. Adv. Anal. Chem. Instrum. 1965, 4, 117-212.

20. Maheriya, P.M. Cyclodextrin: A promising candidate in enhancing oral bioavailability of poorly water soluble drugs. $M O J$ Bioequiv. Bioavailab. (MOJBB) 2017, 3, 60-63. [CrossRef]

21. Ono, N.; Hirayama, F.; Arima, H.; Uekama, K. Analysis of the phase solubility diagram of a phenacetin/competitor/ $\beta$ cyclodextrin ternary system, involving competitive inclusion complexation. Chem. Pharm. Bull. 2001, 49, 78-81. [CrossRef]

22. Bayrakc, M.; Ertul, Ş.; Yilmaz, M. Phase solubility studies of poorly soluble drug molecules by using O-phosphorylated calixarenes as drug-solubilizing agents. J. Chem. Eng. Data 2012, 57, 233-239. [CrossRef]

23. Boonyarattanakalin, K.; Viernstein, H.; Wolschann, P.; Lawtrakul, L. Influence of ethanol as a Co-Solvent in cyclodextrin inclusion complexation: A Molecular Dynamics Study. Sci. Pharm. 2015, 83, 387-399. [CrossRef] [PubMed]

24. Yuan, C.; Liu, B.; Liu, H. Characterization of hydroxypropyl- $\beta$-cyclodextrins with different substitution patterns via FTIR, GC-MS, and TG-DTA. Carbohydr. Polym. 2015, 118, 36-40. [CrossRef] [PubMed]

25. Mali, A.J.; Pawar, A.P.; Purohit, R.N. Development of Budesonide Loaded Biopolymer Based Dry Powder Inhaler: Optimization, In Vitro Deposition, and Cytotoxicity Study. J. Pharm. 2014, 2014, 795271. [CrossRef] [PubMed]

26. Oliveira, A.P.; Silva, A.L.N.; Viana, L.G.F.C.; Silva, M.G.; Lavor, É.M.; Oliveira-Júnior, R.G.; Alencar-Filho, E.B.; Lima, R.S.; Mendes, R.L.; Rolim, L.A.; et al. $\beta$-Cyclodextrin complex improves the bioavailability and antitumor potential of cirsiliol, a flavone isolated from Leonotis nepetifolia (Lamiaceae). Heliyon 2019, 5, 1692. [CrossRef] [PubMed]

27. Musuc, A.M.; Anuta, V.; Atkinson, I.; Sarbu, I.; Popa, V.T.; Munteanu, C.; Mircioiu, C.; Ozon, E.A.; Nitulescu, G.M.; Mitu, M.A. Formulation of chewable tablets containing carbamazepine- $\beta$-cyclodextrin inclusion complex and f-melt disintegration excipient. The mathematical modeling of the release kinetics of carbamazepine. Pharmaceutics 2021, 13, 915. [CrossRef] [PubMed]

28. Rachmawati, H.; Edityaningrum, C.A.; Mauludin, R. Molecular Inclusion Complex of Curcumin- $\beta$-Cyclodextrin Nanoparticle to Enhance Curcumin Skin Permeability from Hydrophilic Matrix Gel. AAPS PharmSciTech 2013, 14, 1303-1312. [CrossRef] [PubMed]

29. Ali, H.; Weigmann, B.; Collnot, E.M.; Khan, S.A.; Windbergs, M.; Lehr, C.M. Budesonide loaded PLGA nanoparticles for targeting the inflamed intestinal mucosa-Pharmaceutical characterization and fluorescence imaging. Pharm. Res. 2016, 33, 1085-1092. [CrossRef] [PubMed]

30. Fanelli, S.; Zimmermann, A.; Totóli, E.G.; Salgado, H.R.N. FTIR Spectrophotometry as a Green Tool for Quantitative Analysis of Drugs: Practical Application to Amoxicillin. J. Chem. 2018, 2018, 3920810. [CrossRef]

31. Sriamornsak, P.; Burapapadh, K. Characterization of recrystallized itraconazole prepared by cooling and anti-solvent crystallization. Asian J. Pharm. Sci. 2015, 10, 230-238. [CrossRef]

32. Mezzena, M.; Scalia, S.; Young, P.M.; Traini, D. Solid lipid budesonide microparticles for controlled release inhalation therapy. AAPS J. 2009, 11, 771-778. [CrossRef] [PubMed]

33. Nikowitz, K.; Pintye-Hódi, K.; Regdon, G. Study of the recrystallization in coated pellets—Effect of coating on API crystallinity. Eur. J. Pharm. Sci. 2013, 48, 563-571. [CrossRef] [PubMed]

34. Ficarra, R.; Ficarra, P.; Di Bella, M.R.; Raneri, D.; Tommasini, S.; Calabrò, M.L.; Gamberini, M.C.; Rustichelli, C. Study of $\beta$-blockers / $\beta$-cyclodextrins inclusion complex by NMR, DSC, X-ray and SEM investigation. J. Pharm. Biomed. Anal. 2000, 23, 33-40. [CrossRef]

35. Sambasevam, K.P.; Mohamad, S.; Sarih, N.M.; Ismail, N.A. Synthesis and characterization of the inclusion complex of $\beta-$ cyclodextrin and azomethine. Int. J. Mol. Sci. 2013, 14, 3671-3682. [CrossRef] [PubMed]

36. Ong, S.G.M.; Ming, L.C.; Lee, K.S.; Yuen, K.H. Influence of the encapsulation efficiency and size of liposome on the oral bioavailability of griseofulvin-loaded liposomes. Pharmaceutics 2016, 8, 25. [CrossRef] [PubMed]

37. Teja, S.B.; Patil, S.P.; Shete, G.; Patel, S.; Bansal, A.K. Drug-excipient behavior in polymeric amorphous solid dispersions. J. Excip. Food Chem. 2014, 4, 70-94.

38. Gharib, R.; Greige-Gerges, H.; Fourmentin, S.; Charcosset, C.; Auezova, L. Liposomes incorporating cyclodextrin-drug inclusion complexes: Current state of knowledge. Carbohydr. Polym. 2015, 129, 175-186. [CrossRef] [PubMed] 
39. Samprasit, W.; Rojanarata, T.; Akkaramongkolporn, P.; Ngawhirunpat, T.; Sila-On, W.; Opanasopit, P. Improvement of drug loading onto ion exchange resin by cyclodextrin inclusion complex. Drug Dev. Ind. Pharm. 2013, 39, 1672-1680. [CrossRef] [PubMed]

40. Karavas, E.; Georgarakis, E.; Sigalas, M.P.; Avgoustakis, K.; Bikiaris, D. Investigation of the release mechanism of a sparingly water-soluble drug from solid dispersions in hydrophilic carriers based on physical state of drug, particle size distribution and drug-polymer interactions. Eur. J. Pharm. Biopharm. 2007, 66, 334-347. [CrossRef] [PubMed]

41. Papageorgiou, G.Z.; Bikiaris, D.; Kanaze, F.I.; Karavas, E.; Stergiou, A.; Georgarakis, E. Tailoring the release rates of fluconazole using solid dispersions in polymer blends. Drug Dev. Ind. Pharm. 2008, 34, 336-346. [CrossRef] [PubMed]

42. Kanaze, F.I.; Kokkalou, E.; Niopas, I.; Georgarakis, M.; Stergiou, A.; Bikiaris, D. Dissolution enhancement of flavonoids by solid dispersion in PVP and PEG matrixes: A comparative study. J. Appl. Polym. Sci. 2006, 102, 460-471. [CrossRef]

43. Ainali, N.M.; Xanthopoulou, E.; Michailidou, G.; Zamboulis, A.; Bikiaris, D.N. Microencapsulation of fluticasone propionate and salmeterol xinafoate in modified chitosan microparticles for release optimization. Molecules 2020, 25, 3888. [CrossRef] [PubMed]

44. Siafaka, P.I.; Okur, N.Ü.; Mone, M.; Giannakopoulou, S.; Er, S.; Pavlidou, E.; Karavas, E.; Bikiaris, D.N. Two different approaches for oral administration of voriconazole loaded formulations: Electrospun fibers versus $\beta$-cyclodextrin complexes. Int. J. Mol. Sci. 2016, 17, 282. [CrossRef] [PubMed] 